\title{
Experimental and numerical investigation of the contact behavior during FE forming simulation of continuously reinforced composites in wet compression molding
}

Cite as: AIP Conference Proceedings 2113, 020002 (2019); https://doi.org/10.1063/1.5112507 Published Online: 02 July 2019

Christian Poppe, Dominik Dörr, Fabian Kraus, and Luise Kärger

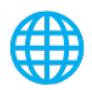

\section{ARTICLES YOU MAY BE INTERESTED IN}

Preface: Proceedings of the 22nd International ESAFORM Conference on Material Forming (ESAFORM 2019)

AIP Conference Proceedings 2113, 010001 (2019); https://doi.org/10.1063/1.5112505

256 shades of gray: Application of image processing to evaluate the effect of sample geometry and constant shear strain rates in the picture-frame test

AIP Conference Proceedings 2113, 020001 (2019); https://doi.org/10.1063/1.5112506

An approach for rapid prediction of textile draping results for variable composite component geometries using deep neural networks

AIP Conference Proceedings 2113, 020007 (2019); https://doi.org/10.1063/1.5112512

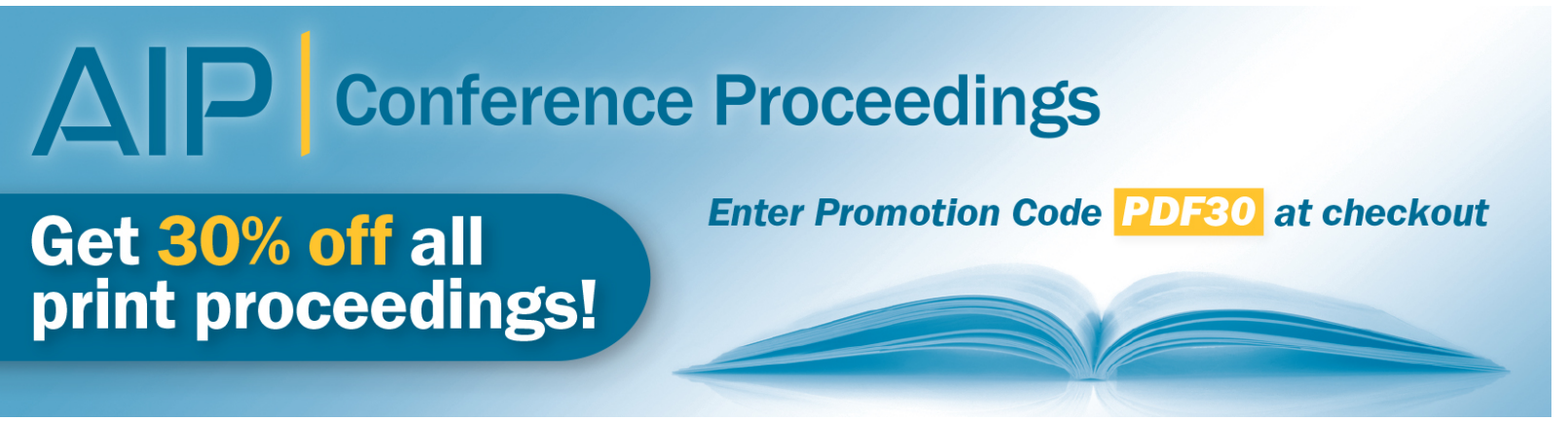




\title{
Experimental and Numerical Investigation of the Contact Behavior during FE Forming Simulation of Continuously Reinforced Composites in Wet Compression Molding
}

\author{
Christian Poppe ${ }^{1, a)}$ Dominik Dörr ${ }^{1}$, Fabian Kraus $^{1}$, Luise Kärger ${ }^{1}$ \\ ${ }^{1}$ Karlsruhe Institute of Technology, Institute for Vehicle System Technology, Chair of Light-Weight Technology, \\ Rintheimer-Querallee 2, 76131 Karlsruhe, Germany \\ a) Corresponding author: christian.poppe@kit.edu
}

\begin{abstract}
Wet compression molding (WCM) provides large-scale production potential for continuously fiber-reinforced structural components due to simultaneous infiltration and draping during molding (viscous draping). Experimental and theoretical investigations proved strong mutual dependencies between resin progression and textile draping. Significant cavity pressures only develop towards the end of the tool stroke, when the cavity is almost filled with resin and fibers. Therefore, the resin's impact on the draping behavior (intra-ply and interface behavior) is of great relevance, since it represents a large share of the draping process. This study extends the work presented by Hüttl et al. [1] with experimental interface tests on dry and infiltrated woven fabrics, which confirm rate-, pressure- and viscosity-dependent tangential contact behavior within the viscous draping stage. Furthermore, experimental results for the ply-ply interface are utilized to parametrizes a contact model, which is subsequently applied to assess and evaluate the process relevance on part level by means of FE forming simulation. Although a relatively simple geometry has been investigated, numerical results show a significant impact of the infiltration-depended tangential contact formulation on part level. Beyond that, an investigation of the ply-ply contact state (pressure or tension) reveal that transversal pressure is only predominate towards the end of the tool stroke. Consequently, contact characterization and parametrization should also include tests at low transversal pressure.
\end{abstract}

\section{INTRODUCTION}

Wet compression molding (WCM) provides large-scale production potential for continuously fiber-reinforced structural components as a promising alternative to resin transfer molding (RTM). Lower cycle times are enabled by parallelization of the process steps draping, infiltration and curing during molding. Key process parameters cannot be predicted in virtual forming analysis due to a lack of knowledge or suitable numerical tools to account for the above outlined dependencies by existing process stimulation approaches [2-4]. Thus, identification, understanding and modelling of the occurring dependencies is needed to enable further development of adequate simulation approaches for the WCM Process. Since, significant cavity pressures only develop towards the end of the tool stroke, when the cavity is almost filled with resin or fibers, the resin's impact on the draping behavior (intra-ply and interface behavior) is of great relevance, since it represents a large shear of the draping process. Regarding intra-ply behavior, experimental and numerical investigations carried out with a modified bias extension test (IBET) revealed both viscosity- and rate-dependent material response for the infiltrated shear behavior with a relevant influence on the viscous draping behavior [3]. Several studies [4-7] show that rate-, pressure- and viscosity dependent material models need to be applied for modelling of the tangential contact behavior for both thermoplastic and thermoset based processes. Beyond that, Hüttl et al. [1] showed that fiber orientation and infiltration state effect the coefficient of friction $(\mathrm{CoF})$ of woven fabrics within the viscous draping stage. Moreover, Nosrat-Nezami et al. [8] presented correlations between the CoF and relative fiber orientations as well as different shear states of the contact plies of dry woven fabrics.

\footnotetext{
Proceedings of the 22nd International ESAFORM Conference on Material Forming AIP Conf. Proc. 2113, 020002-1-020002-6; https://doi.org/10.1063/1.5112507 Published by AIP Publishing. 978-0-7354-1847-9/\$30.00
} 
In this work, experimental results of tangential contact behavior of dry and infiltrated woven fabrics are presented, considering different infiltration viscosities, contact velocities and transversal pressures. Moreover, an existing contact model, implemented in ABAQUS [7,9], is parametrized with the obtained experimental results to assess the relevance on part level by means of FE forming simulation. Beyond that, the numerical model is used to evaluate the contact state (tension or pressure) between the plies during the viscous draping.

\section{EXPERIMENTAL PART}

An experimental test set-up, according to Figure 1 (a) and Figure 2 (a), comprising an infiltratable sliding surface in conjunction with a rope-guided sled, mounted on a tensile testing machine of the company Zwick GmbH \& Co. KG (Germany), as presented in [1] used. In this study, a SIGMATEX (GB) 12K carbon fibre woven fabric without binder is used. It consist of T700SC-12K-50C Zoltek fibres. The area weight is $330 \pm 10 \mathrm{~g} / \mathrm{m}^{2}$ and roving width is 5.0 $\pm 0.5 \mathrm{~mm}$, while the initial spacing measures $2.0 \pm 0.3 \mathrm{~mm}$. Silicon oils with three rate-independent viscosities $(20$, $135,250 \pm 3 \mathrm{mPas}$ ) are used to avoid additional heating of the test bench and related uncertainties regarding local temperature distribution. To investigate the rate-dependency of tangential contact behavior, three different displacement velocities are applied during the experiments $(100,350,700 \mathrm{~mm} / \mathrm{min})$. Two contact pairs are investigated, namely the ply-tool and ply-ply. Thus, in contrast to Hüttl et al. [1], this study focuses on the effects of rate- and transversal pressure dependency of infiltrated contact interfaces within the viscous draping stage and not on relative fiber orientations during quasi-static conditions. Furthermore, only undeformed fabrics in terms of shear are investigated. To investigate a potential pressure-dependency, two different weights (718 g and $1218 \mathrm{~g})$ are used for the sled with a contact area of $3600 \mathrm{~mm}^{2}$. To account for a homogeneous and comparable inflation state, the same amount of resin is applied during each experiment on top of the clamped fabric. In order to minimize drag forces of the fluid, only the amount of resin needed for a homogeneous and complete infiltration is applied. A time period of two minutes is waited until the resin is distributed within the test bench prior to testing. Subsequently, the sled is placed at a constant starting position on the sliding surface and another minute is waited to ensure contact infiltration.

\section{Experimental results and discussion}

The experimental results for the tool-ply contact pair are presented in Figure 1. The tangential stress does significantly depend on slip-rate and viscosity of resin. The impact of infiltration increases with increasing sled weight. Moreover, rate-dependency increases along with contact viscosity.

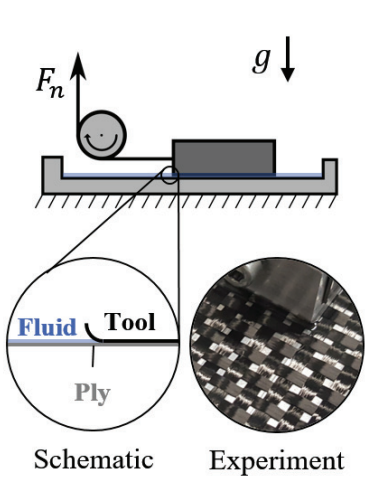

(a)



(b)

FIGURE 1. Experimental test set-up and tangential stresses of the tool-ply contact for a fiber orientation of $0 / 90^{\circ}$ under different infiltration states; (a) Test set-up, (b) Results with a constant sled weight of $718 \mathrm{~g}$ and $1218 \mathrm{~g}$.

Furthermore, the experimental results of the ply-ply contact pair are presented in Figure 2, using the same parameter combinations. In contrast to the tool-ply contact, a contact infiltration leads to reduces tangential stresses and the ratedependency is less pronounced. The viscosity impact increases with increases sled weight, similar to tool-ply contact. 


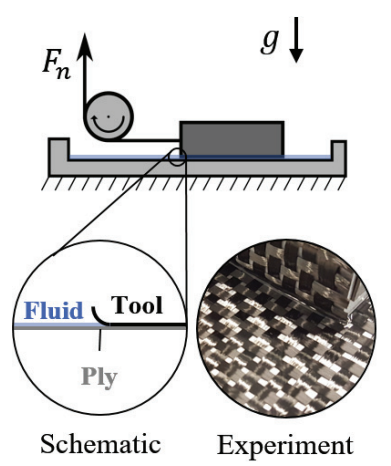

(a)

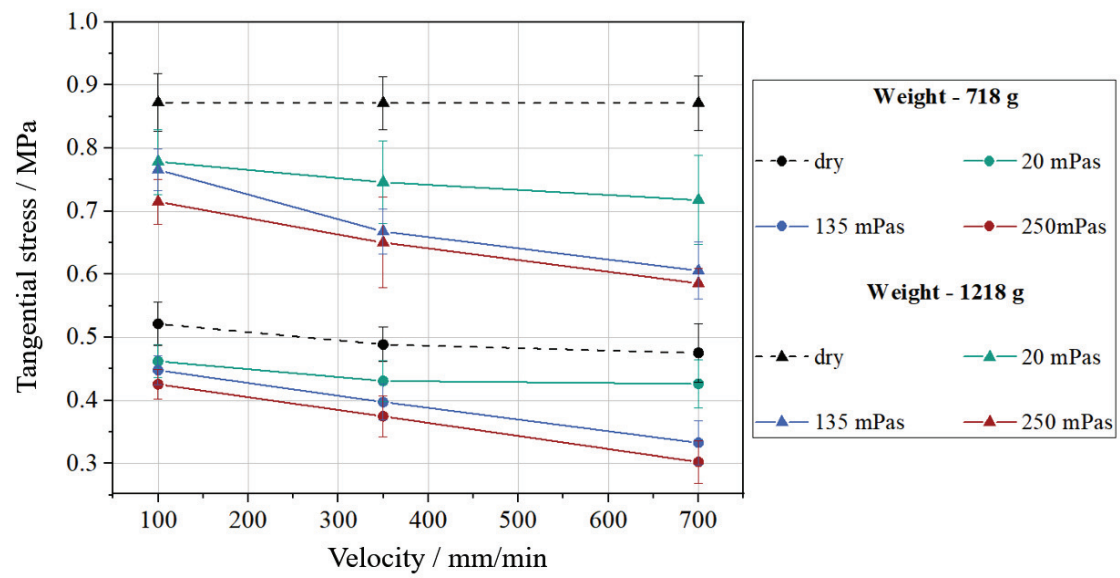

(b)

FIGURE 2. Experimental test set-up and tangential stresses of the ply-ply contact with $0 / 90^{\circ}$ fiber orientation under different infiltration conditions; (a) Test set-up, (b) Results with a constant sled weight of $718 \mathrm{~g}$ and $1218 \mathrm{~g}$.

Regarding the experiments with the tool-ply contact pair (cf. Figure 1), the tool provides a smooth, rigid contact interface. Therefore, the scattering of the test results is low, compared to the ply-ply contact. Furthermore, the closed contact surface of the tool enables a hydrodynamic friction state, which leads to a complete separation of the contact interfaces of tool and ply. This separation could be confirmed by optical measurements during experiments. The obtained results are therefore dominated by the fluid behavior. Consequently, the tangential stress increase along with contact velocity and viscosity. Note that due to fluid displacement caused by the sled, the formation low-pressure zones below the sled cannot be excluded completely.

Regarding the experiments of the ply-ply interface (cf. Figure 2), both contact surfaces are heterogeneous and deformable, which can lead to interlocking of fibers and mixed contacted states during the experiments. Therefore, scattering of the results is higher compared to the tool-ply ones. In addition, the gaps between the rovings in conjunction with the surface structure prevents a proper separation of the contact pairs - a hydrodynamic friction state can only be assumed locally. The contact infiltration leads to a lubrification of the contact areas with leads to a reduced coefficient of friction (COF) (cf. Table 1). Since the contact is in a mixed state, the rate-dependency is therefore less pronounced compared to the tool-ply contact. The results of the test with low contact velocities are in agreement with the results presented by Hüttl. et.al. [1], which could be extended by rate- and pressure dependent results for the same material combination.

\section{NUMERICAL PART}

In the following, FE forming simulation is utilized to assess and evaluate the process relevance of the experimental findings of the ply-ply interface on a generic double dome geometry. On macroscopic scale, FE forming simulation bases on constitutive modelling of the relevant deformation mechanisms during forming, which are usually categorized according to intra-ply and interface mechanisms. All constitutive models are implemented within the commercially available FE solver ABAQUS by means of several user-subroutines [3,7,9]. To account for a decoupled membrane and bending behavior, superimposed membrane and shell elements are applied to represent the single layer of the stacked laminate. The membrane model is parametrized according to previously published experimental shear analysis of the same material [3]. For bending modelling, an existing hypoviscoelastic model presented by Dörr et al. [9] is applied. To limit the numerical investigation to the influence of the contact behavior, only the dry parameter set are used for the membrane and bending behavior during all simulations, which leads to a constant, rate-independent intra-ply behavior. Regarding the interface-mechanisms, a contact formulation based on the approach presented by Dörr et al. [7] is applied, adopted and described in the following. 


\section{Numerical contact model}

Regarding the modelling of the contact behavior, normal traction $N$ and tangential traction $\boldsymbol{T}$ are naturally described separately. Penetration resistance and adhesion is obtained by suitable constitutive equations in normal direction (cf. Figure 3(a)), whereas sticking and sliding is accounted for in the constitutive equations in tangential direction according to Figure 3(b)).

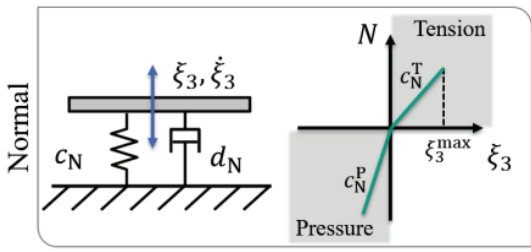

(a)

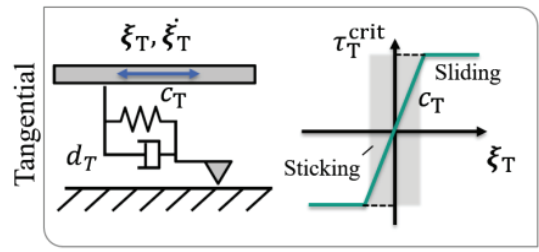

(b)

FIGURE 3. Schematic illustration of the applied contact modelling approach and correlation in normal (a) and tangential (b) direction within the local contact coordinate system $\xi_{i}$.

Normal traction. To account for penetration resistance and adhesion between the plies, two penalty stiffnesses $c_{\mathrm{n}}^{T}$ and $c_{\mathrm{n}}^{P}$ along with a penalty damping $d_{\mathrm{n}}$ are introduced. The normal traction $N$ within the local contact coordinate system $\xi_{i}$ is calculated according to

$$
N=\left\{\begin{array}{lll}
0 & , \xi_{3} \geq \xi_{3}^{\max } & \text { (no contact) } \\
c_{\mathrm{N}}^{\mathrm{T}} \xi_{3}+d_{\mathrm{N}} \dot{\xi}_{3} & , 0 \leq \xi_{3}<\xi_{3}^{\max } & \text { (adhesion) } \\
c_{\mathrm{N}}^{\mathrm{P}} \xi_{3}+d_{\mathrm{N}} \dot{\xi}_{3} & , \xi_{3}<0 & \text { (penetration) }
\end{array}\right.
$$

where $\xi_{3}$ is the relative contact displacement and $\dot{\xi}_{3}$ the corresponding velocity. As shown in Figure 3 (a), tension within the contact is only accounted for until a maximal admissible distance $\xi_{3}^{\max }$.

Tangential traction. An isotropic constitutive equation for friction is applied to account for the transition from sticking to sliding by means of an isotropic yield function $\Phi$. Hence, relative fiber orientation is not taken into account. The stick-slip-condition of the tangential traction $\boldsymbol{T}$ is regularized by the penalty-method by

$$
\boldsymbol{T}=\left\{\begin{array}{lll}
c_{\mathrm{T}} \xi_{\mathrm{T}}+d_{\mathrm{T}} \dot{\xi}_{\mathrm{T}} & , \Phi \leq 0 \\
\tau_{\mathrm{T}}^{\text {crit }} \frac{\dot{\xi_{\mathrm{T}}}}{\left\|\dot{\xi}_{\mathrm{T}}\right\|} & , \Phi>0 & \text { (sticking) }
\end{array},\right.
$$

where $\xi_{T}$ is the relative tangential displacement. The critical tangential stress $\tau_{\mathrm{T}}^{\text {crit }}$ (cf. Figure 4 (b)) is modelled by means of a Coulomb friction law superimposed with a Cross model to account for the rate- and pressure dependent intra-ply slip behavior between the infiltrated plies according to

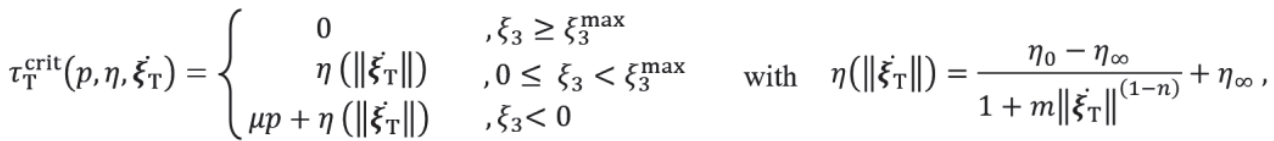

where $\mu$ and $\eta$ provide the material parameters, which depend on the actual tangential contact velocity $\dot{\xi}_{T}$ and the contact pressure $p$, respectively.

TABLE 1. Summary of the determined material parameters for tangential ply-ply interface.

\begin{tabular}{cccccc}
\hline Infiltration state & $\mu /-$ & $\eta_{0} / \mathrm{MPas} / \mathrm{mm}$ & $\eta_{\infty} / \mathrm{MPas} / \mathrm{mm}$ & $\mathrm{m} / \mathrm{MPas} / \mathrm{mm}$ & $\mathrm{n} /-$ \\
\hline dry & 0.290 & $1 \mathrm{E}-07$ & $1 \mathrm{E}-07$ & 1 & 1 \\
$20 \mathrm{mPas}$ & 0.223 & $1 \mathrm{E}-04$ & $2 \mathrm{E}-06$ & 0.01 & -5.0 \\
$135 \mathrm{mPas}$ & 0.203 & $9 \mathrm{E}-05$ & $3 \mathrm{E}-06$ & 0.01 & -5.0 \\
$250 \mathrm{mPas}$ & 0.185 & $7 \mathrm{E}-05$ & $5 \mathrm{E}-06$ & 0.01 & -5.0 \\
\hline
\end{tabular}

To limit the numerical investigations to the influence of the tangential contact behavior, constant parameters are used for the normal behavior in this study. The tangential material parameters $\mu$ and $\eta$ are determined for each infiltration state according to Table 1 by comparison with the experimental results (cf. Figure 2). 


\section{FE forming simulation model and numerical results}

The presented numerical contact model in conjunction with the above outlined FE forming simulation approach is applied to the simulation setup of a double dome geometry according to Figure 5 (a). Simulations containing two plies with initial fiber orientations of $0 / 90^{\circ}$ and $\pm 45^{\circ}$ are conducted with a linear closing speed of $10 \mathrm{~mm} / \mathrm{s}$, implemented via a displacement boundary condition. The critical tangential stress $\tau_{\mathrm{T}, 45}^{\text {crit }}$ is reduced by $30 \%$ to account for the relative contact orientation of $\pm 45^{\circ}$ according to the results presented by Hüttl et al. [1]. Preliminary studies show that the occurring tangential velocities at the ply-ply interface remain within the parametrized range (cf. Figure 4 (b)).

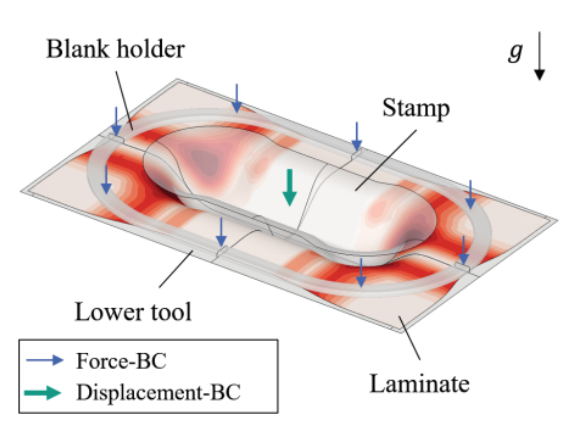

(a)

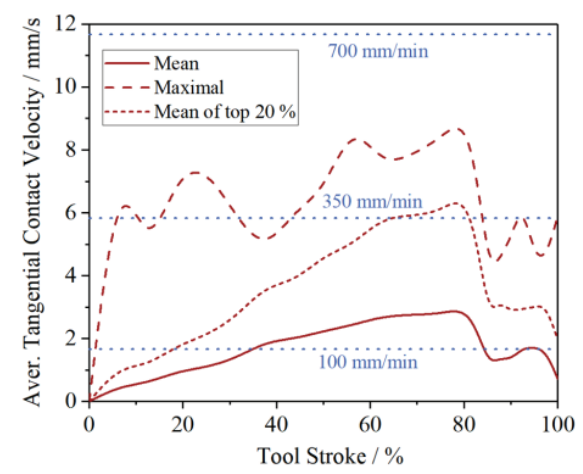

(b)

FIGURE 4. (a) FE forming simulation set-up with surrounding blank holder and applied boundary conditions; (b) Comparison of the parametrized and occurring averaged tangential contact velocities during forming.

Tool surfaces are modelled using rigid elements and gravity is taken into account. An additional global blank holder with a constant pressure of $60 \mathrm{~N}$ is used to emphasize the tangential friction during forming. Tool-ply contact is implemented via a built-in routine in ABAQUS using a constant CoF of $\mu_{\text {tool }}=0.3$. Thus, the above outlined contact model is only applied to the ply-ply interface.

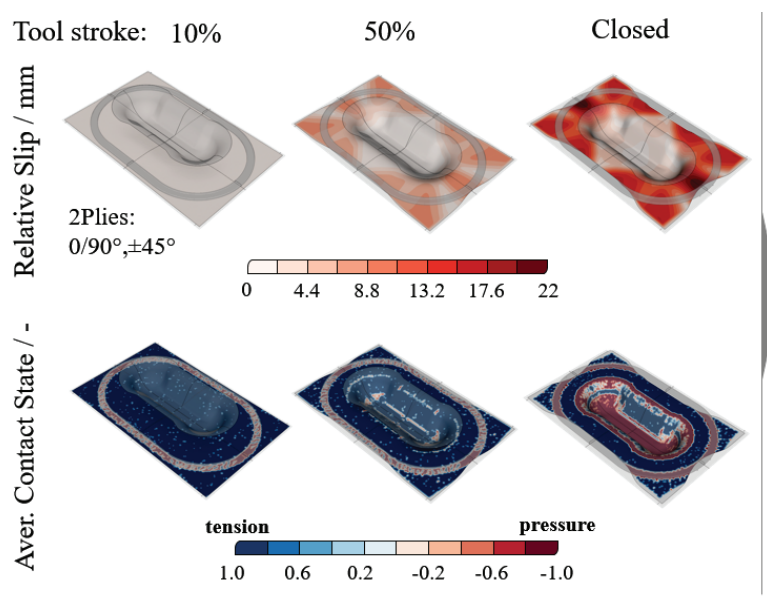

(a)

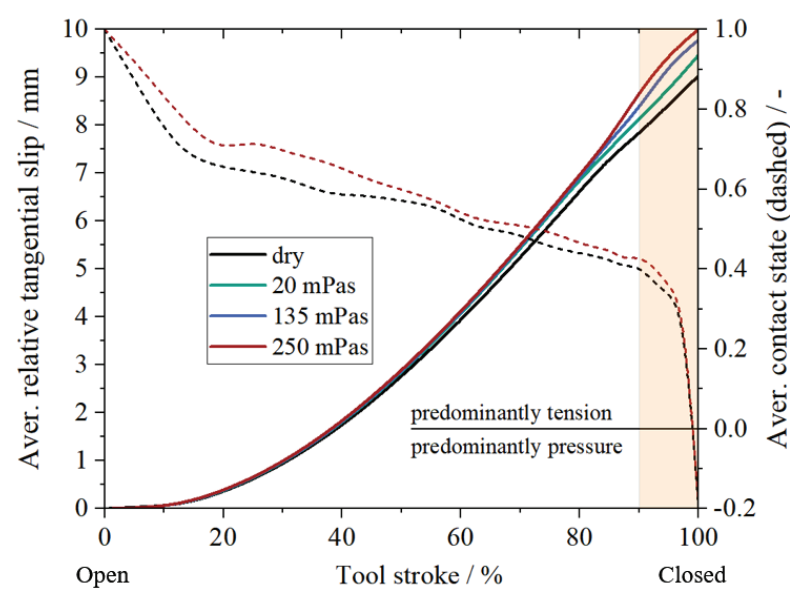

(b)

FIGURE 5. Illustration of the viscosity dependent relative tangential slip; (a) Actual relative between the plies at discrete states; (b) Averaged slip and contact state (1=Tension, $-1=$ Pressure) within the final tool shape.

Individual deformation of the two plies leads to relative slip. As Figure 5 illustrates, the final tangential slip depends on the infiltration state. The identification of material parameter show that the lubrification of the contact interfaces mainly leads to reduced COFs between the plies. Consequently, significant differences in terms of relative slip between the plies mainly occur within the last stage of the tool stroke when the contact state is pressure dominated. 


\section{DISCUSSION AND CONCLUSION}

The contact behavior of infiltrated woven fabric has been investigated by means of experimental and numerical investigations. Experimental results reveal a countervailing influence of infiltration regarding the investigated contact pairs. Whereas tangential stresses increase with increasing viscosity for the tool-ply contact, they decrease with regard the ply-ply contact. Still, both contact pairs show rate-and viscosity dependent tangential contact behavior. The differences between the closed tool interfaces and the heterogeneous, deformable ply interface are assumed to be the reason for the contrary behavior. Furthermore, experimental results of the ply-ply contact are used to parametrize a corresponding numerical contact model. Identification of the material parameters revealed that the lubrification between the plies mainly reduces the COF, whereas the rate-dependency is of minor importance. Subsequently, the parametrized contact model is used to access the process relevance on part level by means of FE forming simulation on a generic double dome geometry. Numerical results show a impact of the infiltration state on the occurring final relative slip between the plies. Consequently, infiltration-dependent contact formulations have to be taken into account for a more accurate process simulation of the viscous draping stage within wet compression molding (WCM) process. Furthermore, contact state results suggest further investigations on the proper characterization and modelling of the so called "tension state", as it accounts for large shear of the draping.

Consequently, future work will focus on deeper analyses of the contact state within viscous draping. This includes further investigations on the different contact states and additional consideration of the presented experimental results of the tool-ply interface. Beyond that, the impact of infiltrated normal contact behavior will be investigated. Overarching objective remains the development of suitable simulation model to account for the simultaneous draping and fluid progression during forming, as well as their interdependence within the viscous draping stage.

\section{ACKNOWLEDGMENTS}

The authors would like to thank the German State Ministry for Science, Research and Art of Baden-Württemberg (MWK) for the funding of the project Forschungsbrücke Karlsruhe-Stuttgart for which the presented work is carried out. Additionally, the authors would like to thank their project partners at Stuttgart University, Institute for Aircraft Design (IFB) under leadership of Prof. Middendorf for the collaboration. The work is part of the Young Investigator Group (YIG) "Tailored Composite Materials for Lightweight Vehicles", generously funded by the Vector Stiftung.

\section{REFERENCES}

1. Hüttl, J., Poppe, C., Albrecht, F., Lorenz, F., Thoma, B., Kärger, L., Middendorf P., Henning, F., "Investigations on friction behaviour and forming simulation of plain woven fabrics for wet compression moulding", conference contribution, Proceedings SAMPE Europe, Stuttgart, Germany (2017)

2. Bergmann, J., Dörmann, H., Lange, R., "Interpreting process data of wet pressing process. Part 1: Theoretical approach", Journal of composite materials Vol. 50, pp. 2399-2407, doi: 10.1177/0021998315604728 (2016)

3. Poppe, C., Dörr, D., Henning, F., Kärger L., "Experimental and numerical investigation of the shear behavior of infiltrated woven fabrics", Composite Part A, Vol 14, 327-337 (2018) https://doi.org/10.1016/j.compositesa.2018.08.018

4. Poppe C.; Dörr, D.; Henning, F.; Kärger, L., “A 2D modeling approach for fluid propagation during FE-forming simulation of continuously reinforced composites in wet compression moulding" Proceedings of the ESAFORM2018, Palermo/Italy, doi: 10.1063/1.5034823 (2018)

5. Sachs, U., et al. "Characterization of the dynamic friction of woven fabrics - Experimental methods and benchmark results", Composite Part A, V67, 289-298, 2014, doi:10.1016/j.compositesa.2014.08.026 (2014)

6. Fetfatsidis, A., Sherwood, A., Chen, J., Jauffres D., "Characterization of the fabric/tool and fabric/fabric friction during the thermostamping process", Int J Mater Form Vol. 2 Suppl 1:165-168, doi: 10.1007/s12289-009-0591-9 (2009)

7. Dörr, D., Faisst, M., Joppich, T., Poppe, C., Henning, F., Kärger, L., "Modelling approach for anisotropic inter-ply slippage in finite element forming simulation of thermoplastic UD-tapes", API Conference Proceedings ESAFROM, doi: $10.1063 / 1.5034806(2018)$

8. Nosrat-Nezami, F., Gereke, T., Cherif, C., "Analyses of interaction mechanisms during forming of multilayer carbon woven fabrics for composite applications" Composite Part A, Vol 84, 406-416, doi: 10.1016/j.compositesa.2016.02.023 (2016)

9. Dörr, D., Schirmaier, F., Henning, F., Kärger, L., "A viscoelastic approach for modeling bending behavior in finite element forming simulation of continuously fiber reinforced composites", Composites Part A, Vol. 94, pp. 113-123 doi:10.1016/j.compositesa.2016.11.027 (2017) 